\title{
Design of Local Agricultural Product based Pre-biotic Industry in Indonesia
}

\section{Didik Purwadi}

Department of Agro-Industrial Technology, Faculty of Agricultural Technology, Gadjah Mada University, Jl. Flora No.1 Bulaksumur 55281, Indonesia

\section{Abstract}

Inulin as Pre biotics have a good opportunity to be developed in Indonesia due to the good potential of agriculture product as raw material. On the other hand, the market prospect of inulin is very potentially to be developed because the demand of this pre biotic is still be imported from other countries. This purpose of this research is financial and market analysis of pre biotic industry.

Corresponding Author

Didik Purwadi

didik@ugm.ac.id

Received: 25 December 2017

Accepted: 5 February 2018

Published: 1 March 2018

Publishing services provided by Knowledge E

(c) Didik Purwadi. This article is distributed under the terms of the Creative Commons

Attribution License, which permits unrestricted use and redistribution provided that the original author and source are credited.

Selection and Peer-review under the responsibility of the ICoA Conference Committee.
Keywords: Pre-biotic, design, feasible

\section{INTRODUCTION}

Pre-biotic industry is an industry that produces various kind of pre-biotic which extracted from various agricultural commodities as well as gembili, Pre-biotic is food ingredient that give impact to stimulate growth. Inulin is the most widely used ingredient in the pre-biotics market owing to easier availability from natural sources [1]. So far, the researches about pre-biotic of inulin-type focus on how to produce it effectively. Moreover this research was done for feasibility study of producing prebiotic inulin regarding their possible use as include the big potential of local agricultural product such as gembili (Dioscorea esculenta). Moreover, Zubaidah and Wilda [2] concluded that dahlia, yam and gembili tubers as raw material of inulin production, shows that the best treatment is isolates of $\mathrm{L}$. casei obtained in the fermentation medium with the addition of inulin from gembili tubers.

The purpose of this research is to develop inulin pre-biotic industry based on gembili tubers as a local agricultural product. The development of this industry should be proven that feasible for marketing, production, financial and operational management. So that this research purpose can be divided into three specific purposes as follows: 1) to provide a financial analysis and 2) market analysis of the inulin pre biotic industry. 


\begin{tabular}{|l|l|l|}
\multicolumn{3}{|c|}{ TABLE 1: Investment components } \\
\hline 1 & Peeling and washing $18,000,000$ \\
\hline 2 & Cutting & $12,250,000$ \\
\hline 3 & Drying & $115,000,000$ \\
\hline 4 & Heating & $110,000,000$ \\
\hline 5 & Mixing & $16,000,000$ \\
\hline 6 & Filtering & $11,000,000$ \\
\hline 7 & freezer & $112,000,000$ \\
\hline 8 & sentrifuge & $110,000,000$ \\
\hline 9 & oven & $115,000,000$ \\
\hline 10 & grinder & $15,000,000$ \\
\hline 11 & screening & $110,000,000$ \\
\hline 12 & packing & $15,000,000$ \\
\hline
\end{tabular}

\section{METHOD}

This research has been done through a system approach which is started to identify the stakeholders through descriptive-qualitative analysis. Financial and market analysis is done through feasibility study. The object of this research includes gembili tubers plantation, harvesting and post harvesting processing, and marketing.

Data can be divided into two parts; primer and secondary data. The primer was conducted through in-depth interview to the stakeholders, includes farmers, farmer's groups, government, university institution, food processing industries. The secondary data was built from governmental institutions reports and other relevant.

\section{FINDINGS AND DISCUSSION}

The stakeholders of pre-biotic industry at least are farmer, academician, company, and food industry. Farmers produce gembili as raw material. Academician develops the technology of processing and tools machinery. Private company manages the production finance and marketing. Various food industries are also as consumers.

In order to discuss the financial and marketing analysis, it should be identify the investment components, fix costs and variable costs. Table 1 describes the investment components list of inulin prebiotic production as follows. 
TABLE 2: Variable Cost

\begin{tabular}{|c|c|c|}
\hline No & Component & Unit cost \\
\hline 1 & Fresh Gembili (kg) & 6,000 \\
\hline 2 & Making Chip & 15,000 \\
\hline 3 & Etanol & 17,500 \\
\hline 4 & Water & 100 \\
\hline 5 & Packaging & 1,000 \\
\hline
\end{tabular}

TABLE 3: Fixed Cost

\begin{tabular}{|c|c|c|c|}
\hline No & Component & month (Rp) & Year (Rp) \\
\hline 1 & Manager wage & $1,200,000$ & $14,400,000$ \\
\hline 2 & Workers wage & $1,000,000$ & $12,000,000$ \\
\hline 3 & Maintenance & $1,000,000$ & $12,000,000$ \\
\hline 4 & Building rent & $1,000,000$ \\
\hline 5 & Depreciation & $8,345,000$ \\
\hline & Total & $47,745,000$ \\
\hline
\end{tabular}

It is assumed that those investment components economically can be used for 10 years. The number of production day is 26 days in a month and in each day produce 10 batches, and each batch is produced $10 \mathrm{~kg}$ gembili tubers. Table 2 shows the variable cost

Table 3 indicates the fix cost of inulin pre-biotic processing which includes salary, maintenance and depreciation.

It can be concluded that the annual total production cost is Rp 913,500,000.- or in other words, it is equivalent to Rp. 167,000.-./ kg of gembili tubers.

In terms of operation management, it is feasible to develop the inulin industry which the production capacity is $100 \mathrm{~kg}$ a day, comprises of 10 bathes a day. The number of workers is 2 persons. It can be get $17.5 \mathrm{~kg}$ inulin powder a day.

This finish product is inulin powder which its selling price is Rp. 300,000 per kg. it can be concluded that the profit in a year is Rp. 724.455.000,-

The demand of pre-biotic tends to increase over next eight years. The chronic disease particularly in matured economies tends increase. Consumption of pre-biotic enables to grow which helps human body to fight against chronic diseases itself. Inulin segment demand was over 200.0 kilo tons in 2015. 
This pre-biotic industry is very prospective business due to the market perspective. The global prebiotics market is expected to reach USD 7.11 billion by 2024, according to a new report by Grand View Research, Inc. growing demand for fiber rich food products is expected to drive the market [3]. So far inulin accounted for over $40.0 \%$ of the global prebiotics market in 2015 in terms of revenue. This industry is also important to be developed because it is one of the important functional products. Inulin is widely used to treat diabetes owing to its increased antioxidant activity thus propelling demand. In addition, rising use of prebiotics in animal feed is expected to drive the demand. Growing emphasis on improving overall health is also expected to fuel product demand over the next eight years.

This industry is also important to be developed because it is one of the important functional products. Inulin is widely used to treat diabetes owing to its increased antioxidant activity thus propelling demand. In addition, rising use of pre-biotics in animal feed is expected to drive the demand. Growing emphasis on improving overall health is also expected to fuel product demand over the next eight years.

\section{CONCLUSION}

Based on the financial and market analysis aspects, it can be concluded that inulin pre-biotic industry is feasible and very prospective to be developed in Indonesia. The annual total production cost is Rp 913,500,000.-, the production capacity is $100 \mathrm{~kg}$ a day, and the profit in a year is Rp. 724.455.000,- The demand of pre-biotic inulin tends to increase, accounted for over $40.0 \%$ of the global pre-biotic market. The stakeholders of pre-biotic industry are farmers, academician, and private company.

\section{References}

[1] Roberfroid, M. B., 2005. Inulin Type Fructans, Functional Food Ingredients. CRC Press LLC., Florida

[2] Zubaidah, Elok., and Wilda Akhadian, 2013, Comparative Study of Inulin Extracts from Dahlia, Yam, and Gembili Tubers as Prebiotic, Food and Nutrition Sciences, $2013,4,8-1$

[3] Anonymous, 2016, Prebiotics Market Analysis By Ingredient (FOS, Inulin, GOS, MOS), By Application (Food \& Beverages, Animal Feed, Dietary Supplements) And Segment Forecasts To 2024, http://www.prnewswire. com/news-releases 